\title{
Fatigue life estimation in a hydrogenerator rotor with cracks using the finite element method
}

\author{
Ednei Pedro Gomes Putini ${ }^{1} \cdot$ Fernando de Azevedo Silva ${ }^{1}$
}

Received: 27 November 2017 / Accepted: 4 August 2018/Published online: 17 August 2018

(C) The Brazilian Society of Mechanical Sciences and Engineering 2018

\begin{abstract}
Fatigue is a mechanical engineering field which has been well studied in recent years. This phenomenon is responsible for causing the great majority of mechanical failures in machine elements. Fatigue analysis in a complex piece with the purpose of determining its durability becomes very complicated when it is performed by means of analytical calculations without the aid of software. Thus, the finite element method, which is studied in several areas and is constantly growing, is the ideal tool for the verification of possible failures due to fatigue in heterogeneous components. This paper offers a numerical simulation by finite element method using the software ANSYS of a hydrogenerator rotor which has presented some cracks. As the manifestation of such defect in hydroelectric plant rotors is not common, it requires a detailed study. The results obtained from this study showed that the cracks in the hydrogenerator rotor have arisen due to fatigue. It has been demonstrated that the method employed is very accurate when it is used correctly and that it provides results which represent reality. Moreover, improved solutions were suggested in order to enlarge the fatigue life of hydrogenerator rotor.
\end{abstract}

Keywords Fatigue $\cdot$ Analysis $\cdot$ Cracks $\cdot$ Hydrogenerator rotor $\cdot$ Finite element method

\section{Introduction}

The rotor is one of the main components of a hydroelectric plant. It transforms mechanical power into electrical power. This mechanical power occurs because of the water contact with the turbine rotor that is mechanically coupled (by shaft) to the generator rotor making the whole set to spin. Rotary equipment can exhibit a great variety of failures. Their accurate identification brings immediate results not only for the unit in operation but also for costs.

According to Norton [1] fatigue is a complex phenomenon of progressive rupture of materials exposed to repeated cycles of stress or deformation. These types of

Technical Editor: Paulo de Tarso Rocha de Mendonça.

Ednei Pedro Gomes Putini

ednei_pedro@yahoo.com.br

Fernando de Azevedo Silva

fernando.azevedo@unesp.br

1 Guaratinguetá School of Engineering, UNESP, São Paulo State University, Av. Dr Ariberto Pereira da Cunha 333 - Pedregulho, Guaratinguetá, SP 12516-410, Brazil failures appear after a period, and they can occur even when the stress is low; it means they are caused by the cyclic stress and not by the maximum stress. Fatigue life is defined as the maximum number of load cycles that a structure can bear in the application before any structural collapse occurs.

Usually mechanical failures arise in weld regions so that the analysis of Pettersson and Barsoum [2] is important to do any evaluation of the fatigue life in welded components. The studied beam has a strict loading cyclic, and hence, there were potential risks of failure due to fatigue. In order to verify the weld quality, several different samples were examined and a great dissipation was observed, mainly in the weld root, where the life in fatigue is more highlighted. The study showed the importance of the post-treatment in welds since without it, it would occur stress concentration and residual stresses, which together with cyclical loads give origin to fatigue failures.

The appearance of a defect due to fatigue because of repetitive loading causes some concern since a defect can appear in other areas of the structure or increase in size over time. Consequently, it is essential to repair and/or to follow it up and, in some situations, it is necessary to replace the damaged piece. Therefore, the study by 
Willmerding et al. [3] in a complex component, such as wind turbine with static and dynamic analysis, showed that safety factors should always be used in the investigation of fatigue. In addition, the standardization of calculations is very useful for increasing safety and reliability. In other words, the actual calculation of fatigue life is achieved when it is done over a long period of time and when the results are compared with field experiments.

With technological advances, it is more and more required not only the refined evaluation of the stressed field at all parts of a piece, but also obtaining results with great precision in a shorter time of calculation and, consequently, the prevention of failures in structural projects. With the improvement in high-performance computers, it is being possible to meet requirements effectively. Computer simulation software is being more and more used in engineering. The numerical method known as finite element method, FEM, is quite used in several areas to solve complex problems, as the results obtained from it are quick and quite reliable.

Xiang et al. [4] studied fatigue failures in a traction motor shaft subjected to high speed. With the help of FEM, the results achieved through simulation were sufficient to predict the fatigue life of the shaft. In similar geometries subjected to rotation, it is essential to create relief radius in sharp corners, for example in the shaft diameters transition. This action avoids stress concentration and, consequently, failures due to fatigue.

The work presented by Feng et al. [5], fatigue analysis in welded steam turbines using finite elements, showed residual stress results very close to those obtained experimentally. Although the rotor study of this article does not investigate residual stresses in weld, it is possible to perceive that the weld might have been responsible for the cracks.

The several types of contact analysis, another parameter of great importance for the accomplishment of this research, were very well evaluated by El-sayed et al. [6]. They presented a numerical procedure to investigate fatigue crack initiation life in railheads. This analysis using the finite element method can represent realistic wheel-rail contact geometry and demonstrated that the plasticity effect must be considered to avoid contact load overestimation.

Due to the rotor complexity, the interface evaluation in each of its components is indispensable, such as the analysis accomplished in pole fixation region by Hildinger et al. [7], who studied fatigue life in the critical region of connection between two members for several hydrogenerator types.

The use of finite element method in order to estimate the fatigue life of a mechanical component has significantly increased in the last decades. At the same time, more studies are being developed and made available at academic world in order to find solutions to countless types of problems.

Thus, the contribution of this study is not only to provide a reliable methodology for fatigue calculation by comparing the results obtained with reality, but also to propose solutions to avoid this kind of damage. Moreover, the study of a hydroelectric plant member brings a great deal of background for the development and the improvement in the mechanical engineering area as it is a multidisciplinary structure. There is no other type of an electrical component whose design and dimensions are influenced by as many factors as the machine impelled by a hydraulic turbine.

\section{Hydrogenerator overview}

The hydrogenerator is one of the main components of a hydroelectric plant. According to Boldea [8], electric power is produced by connecting a prime mover that converts the mechanical energy (turbine) to an electrical generator, which, then, converts the mechanical energy into electrical energy.

The rotational speed of a hydroelectric generator is precisely at a synchronized speed with the power-frequency, and because they have constant rotation under conditions of varying loading, the hydrogenerators are known as synchronous machines, Fink and Beaty [9]. Although the name suggests that it is only an electrical equipment, the most of its components are mechanical and they need to be mechanically designed.

In this study a fatigue analysis is presented on the rotating element of a large vertical generator (rotor of Foz do Areia Hydropower Plant). According to Fig. 1, the rotor is composed of six main components: upper shaft, poles, rotor rim, rotor spider, thrust ring and lower shaft. Each rotor piece has extremely important functions for the correct operation of the whole plant.

The upper shaft has the function of connecting the rotor to the collector ring or exciter, and it generally has an extension whose purpose is to transmit radial forces from the rotating part to upper guide bearing, if there is this kind of construction.

The poles are responsible for generating a magnetic field that will induce electric current to the stator. They bear centrifugal forces and give stability to the shaft line. They consist of a coil and a core. The interface with the magnetic ring is extremely critical because cracks might appear. That is the reason why deeper studies are being developed for poles, such as Hildinger et al. [7].

The rotor rim has the largest portion of inertia in all rotating set providing stability for the shaft line. It is 
Fig. 1 Schematic representation of rotor hydrogenerator and components
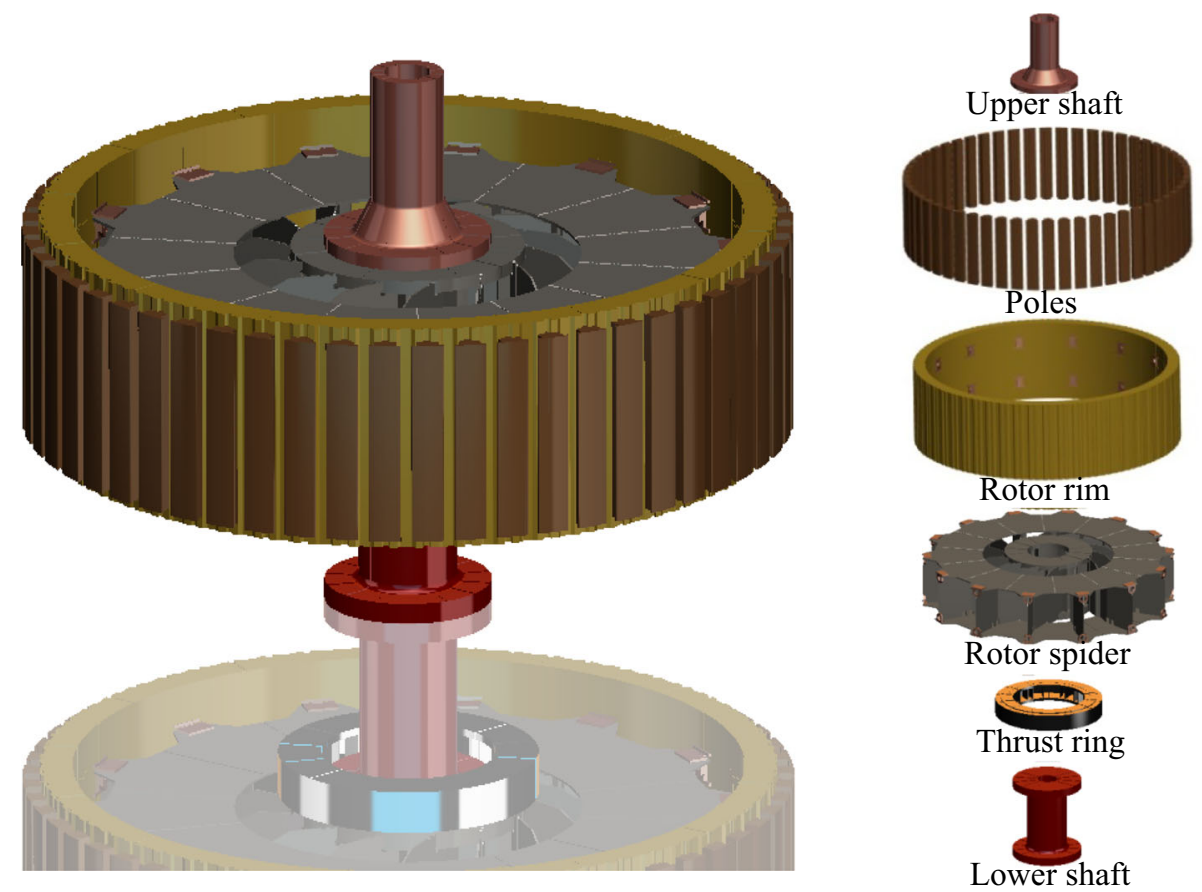

responsible for transmitting torques of shaft to poles and keeping them fixed to the rotor.

The rotor spider is responsible for supporting the rotor rim where axial forces are discharged due to the weight of the rotor rim and of the poles. It also ventilates the rotor and works as a guide for rotor rim expansion. During maintenance the weight of all rotating parts (turbine and generator) is supported by the spider.

The thrust ring transmits axial loads of any rotating set on thrust bearing discharging all rotating weight on this member. In addition, in some cases, the thrust ring transmits radial load when it is a combined bearing construction (thrust bearing with guide bearing).

The lower shaft couples the rotor to turbine shaft and transmits the torque coming from it and having, in some cases, an extension that works as the thrust ring.

\section{Methodology}

In 2009, it was verified the appearance of cracks in rotor spider arms of Foz do Areia Hydropower Plant. In order to investigate the fatigue life of this component, a three-dimensional model was made using CAD Pro-Engineer. Later it was exported to CAE ANSYS, which made the computational simulation of the structure behavior.

\subsection{General data}

The hydroelectric plant also known as Governador Bento Munhoz da Rocha Netto Plant is located in Pinhão, a town that is $240 \mathrm{~km}$ from Curitiba, the capital of Paraná state. It has four generator units with a maximum total power of 1674 [MW]. The operational characteristics of the studied hydrogenerator are presented in Table 1.

\subsection{Materials and criteria}

The materials used in rotor of Foz do Areia Hydropower Plant, as well as the mechanical properties of each one, are described in Table 2.

The verification of rotor mechanical behavior is done by Von Mises stresses, which represent the triaxial state of stresses or take into account all the acting stresses: primary, secondary and peak.

Table 1 Generator general data

\begin{tabular}{ll}
\hline General data & \\
\hline Normal apparent power (kVA) & $415,000.0$ \\
Maximum apparent power (KVA) & $465,000.0$ \\
Power factor & 0.9 \\
Voltage (v) & $16,500.0$ \\
Frequency (Hz) & 60.0 \\
Synchronous/nominal speed (rpm) & 128.6 \\
Load rejection speed (rpm) & 141.5 \\
Runaway speed (rpm) & 246.9 \\
Rotor diameter (mm) & $11,542.0$ \\
Poles number & 56.0 \\
\hline
\end{tabular}


Table 2 Materials

\begin{tabular}{llll}
\hline Component & Material & Yield strength, $S_{\mathrm{y}}(\mathrm{MPa})$ & Ultimate strength, $S_{\text {ut }}(\mathrm{MPa})$ \\
\hline Lower/upper shaft & ASTM 668-D & 260.0 & 517.0 \\
Rotor spider (arms and disks) & ASTM A-36 & 250.0 & 400.0 \\
Rotor spider (hub) & ASTM A-516 G70 & 260.0 & 485.0 \\
Rotor rim sheets & Stahl Blech & 450.0 & 690.0 \\
Pole core sheets & QC & 290.0 & 400.0 \\
\hline
\end{tabular}

The analysis of primary stresses, secondary stresses and fatigue was carried out in accordance with the criteria defined by ASME [10]. Table 3 shows the criteria for each type of stress.

The admissible stress $\left(S_{\mathrm{adm}}\right)$ is the limit value of the stress to which a given material can withstand in certain conditions.

The defined criteria are a function of material mechanical properties, basically as a function of the ultimate strength $\left(S_{\mathrm{ut}}\right)$ and yield strength $\left(S_{\mathrm{y}}\right)$, where $S_{\mathrm{ut}}$ is the maximum stress that can be supported by a material under tensile before failure or rupture. And $S_{\mathrm{y}}$ is the maximum stress sustained by the elastic deformation regime, is the point where the irrecoverable, or plastic deformation begins.

The general primary membrane stress $(\mathrm{Pm})$ is the superficial stress along the cross section, caused by distributed efforts, for example an internal pressure. The primary membrane local stress $(\mathrm{Pl})$ is originated through the mean value along the thickness of a section. The primary bending stress $(\mathrm{Pb})$ is the stress due to flexion along the cross section.

Secondary stresses $(Q)$ are normal stresses or shear stresses developed by constraints of the adjacent parts or by self-restraint of a structure. Small distortions can satisfy the conditions that cause secondary stresses, and structure failure is not expected due to secondary stresses. Secondary stresses are localized and only exist when there are primary stresses.

Table 3 Criteria

\begin{tabular}{ll}
\hline Stress type & Criteria \\
\hline $\mathrm{Pm}$ & $S_{\text {adm }}=\operatorname{minimum}\left(S_{\mathrm{ut}} / 2.4 ; S_{\mathrm{y}} / 1.5\right)$ \\
$\mathrm{Pl}+\mathrm{Pb}$ & $1.5 S_{\text {adm }}$ \\
$\mathrm{Pl}+\mathrm{Pb}+\mathrm{Q}$ & $S_{\mathrm{y}} / S_{\mathrm{ut}}>0.73 S_{\text {adm }}$ \\
& $S_{\mathrm{y}} / S_{\mathrm{ut}} \leq 0.7 \max \left(3 S_{\text {adm }} ; 2 S_{\mathrm{y}}\right)$ \\
$\mathrm{Pl}+\mathrm{Pb}+\mathrm{Q}+\mathrm{F}$ & Fatigue analysis \\
\hline
\end{tabular}

For the cases where the stress is classified as peak according to ASME [10], a fatigue analysis must be performed in order to verify the structure damage due to the cyclic action of this stress type during the component useful life
The basic characteristic of the peak stresses $(F)$ is that it does not cause any appreciable distortions. Peak stress is reprehensible only as a possible source of fatigue failure. Stress concentration and regions of structural discontinuity are examples of this category.

In the evaluation of fatigue life for stresses characterized as peak, Goodman's theory is considered as a design criteria.

\subsection{Problem definition}

Foz do Areia Hydropower Plant rotor cracks were identified in 2009 with some evolution in the process. No detailed inspections were done before, so it is unclear when the problem has begun. The last machine to come into operation was unit 4 in 1982, and as the cracks were detected in units 1,3 and 4 , it is possible to estimate that the problem started in less than 27 years of operation.

The cracks developed in two spots of rotor spider arms: one was close to the union of the upper disk and the other adjacent and in the transition of the lower disk. Figure 2 shows the crack in the upper region, and Fig. 3 illustrates the damage in the lower zone.

\subsection{Model discretization and mesh}

As the pieces and loads are symmetrical, an opportunity to reduce the computational time of simulation was observed. The complete model is extremely inopportune and loads the computational model too much. Thus, only one sector of model was used or $1 / 14$ of the rotor and, with the symmetry command, it was possible to obtain real results and greater speed. Figure 4 shows the Pro-Engineer model of only one sector.

All rotor evaluation was done using the finite element program, ANSYS Workbench v15.0, in structural module. The software used in many engineering areas is capable of solving from simple problems to flow simulations (analysis between fluid and structure). In addition, ANSYS has userfriendly interaction where load and constraint insertion are quite simple and visual. It is worth mentioning that ANSYS has an interface with several CAD software, including the 


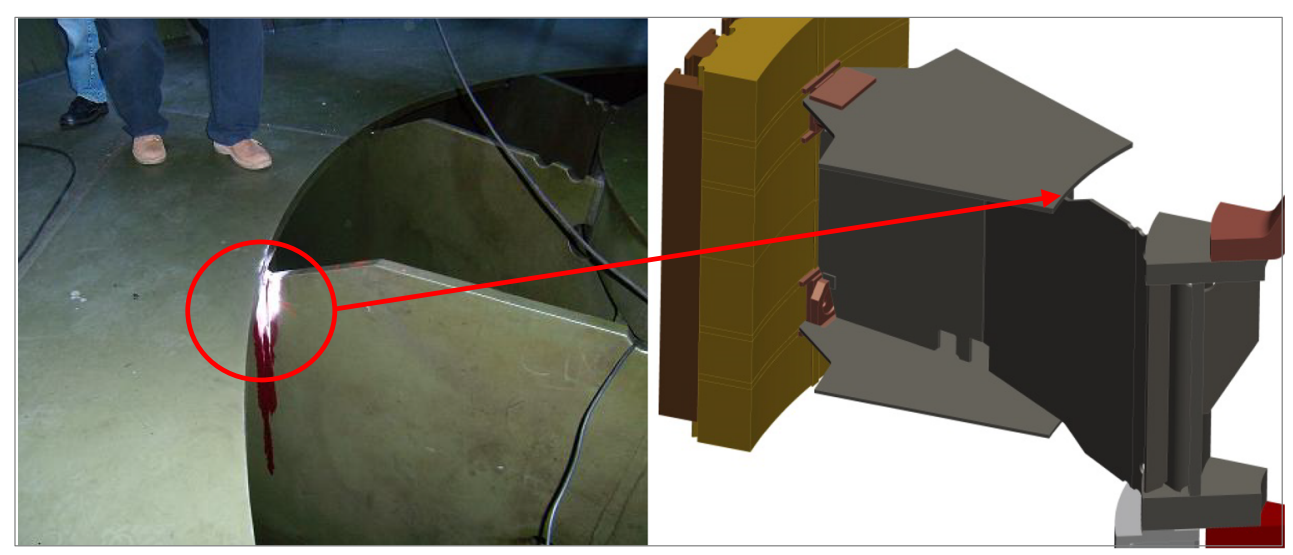

Fig. 2 Cracks in rotor spider arms-upper region

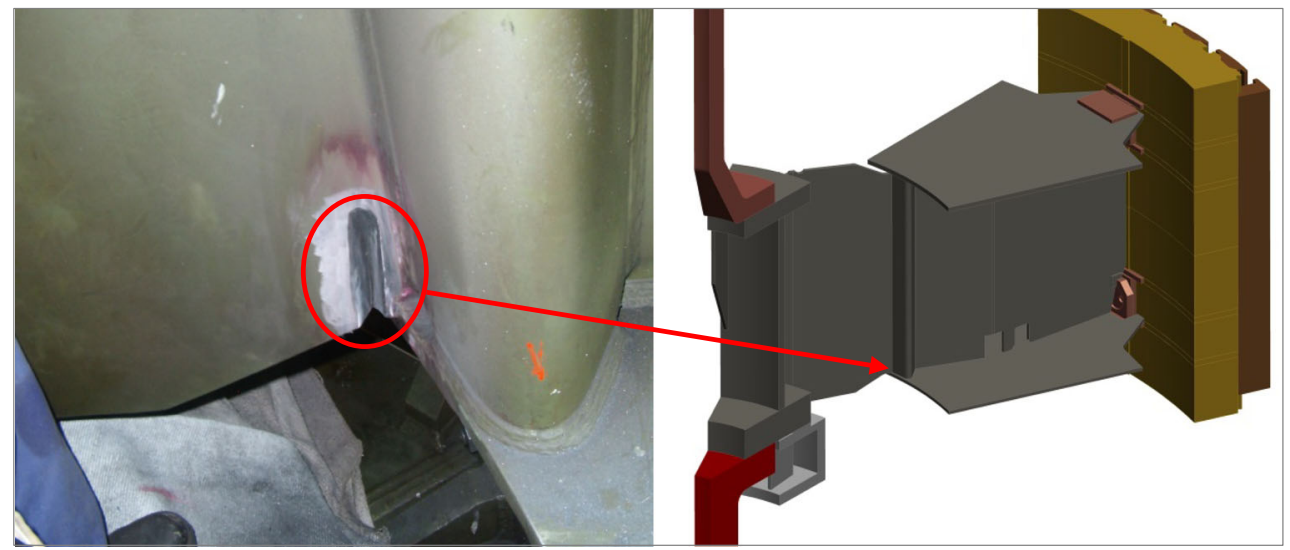

Fig. 3 Cracks in rotor spider arms-lower region

one used to make the rotor model. Although the structure is complex, the program is able to process and obtain results that are close to reality.

For rotor mechanical analysis it was used as the structural element SOLID186 for hexahedral and SOLID187 for

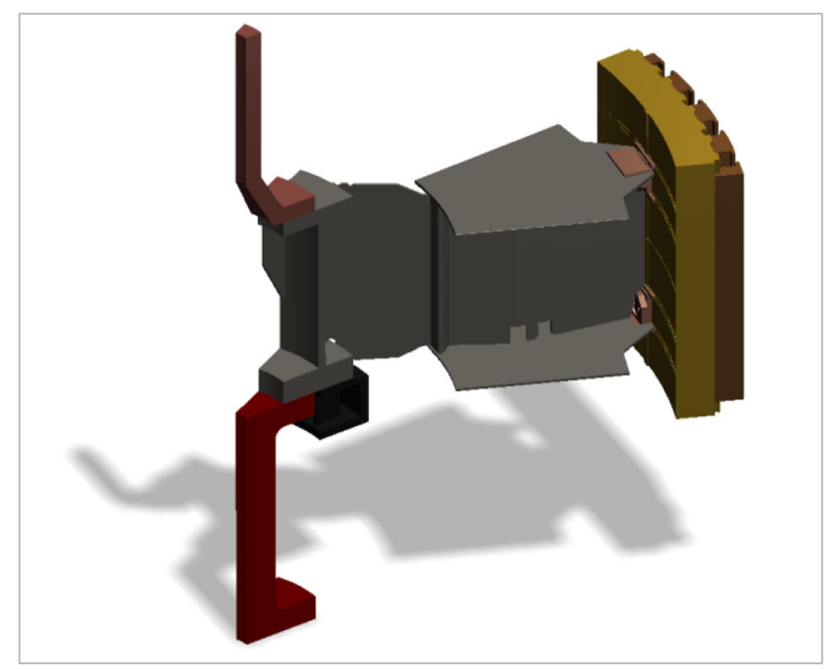

Fig. 4 1/14 rotor model tetrahedral (standard). The difference between them is that the first one is defined by 20 nodes and the second one by 10 nodes. Both have three degrees of freedom at each node: displacements in the $\mathrm{x}, \mathrm{y}$ and $\mathrm{z}$ directions.

Another important parameter for constructing a quality mesh, as mentioned before, is the element size. It is defined from tests (mesh convergence) in order to get the optimal element size in each member, affecting directly the results.

Due to high stresses in some regions of rotor spider, a larger mesh refining was essential in these sites. Without this process, the quality of the elements would be impaired and the results would not represent reality.

With the evaluation of only one sector, the generated mesh did not overload the model very much; in fact, when using refinement, the mesh becomes a little denser but not enough to permit the overloading of the model as it is $1 / 14$ (symmetrical). The unrefined mesh, as the first convergence assessment, observed in Fig. 5, has 61,467 elements and 222,657 nodes.

After preliminary tests with the mesh of Fig. 5, critical stress points (for example, stress concentration) were detected, especially in the spider arms, close to the disks 
(exactly where the cracks occurred). Therefore, it is necessary to perform a convergence test. Such regions of interest are refined up to results that tend toward a single value. Thus, with the convergence tool to automate an adaptive refinement available in CAE ANSYS Workbench, it is possible to obtain the ideal mesh according to the criteria established by the user avoiding all expensive manual work. In the model of this study, a difference less or equal to one percent $(1 \%)$ was used as convergence criterion.

The final refined mesh, whose results converged to a single value, can be visualized in Fig. 6 with 149,589 elements and 371,598 nodes.

\subsection{Considerations}

Cracks did not appear in some rotor elements, and besides they do not have high stresses. Therefore, they were modeled with some simplifications to contribute with stiffness, weight and inertia. For example, it is impractical to model the stacking of rotor rim plates. Thus, for this component, created as a solid, the modulus of elasticity (stiffness) was changed, in order to approximate to the real situation. Hence, with the data of centrifugal force and radial displacement of this piece, the value $E=130,037$ [MPa] was reached.

With the mesh refinements previously mentioned, in regions of numerical singularities as the intersection of spider arm and the disks, it was necessary to model the weld with relief radius to avoid the occurrence of stress that do not represent reality.

The presence of several parts to compose the rotor generator produces the appearance of interfaces that must be evaluated carefully in order to prevent mistakes. For rotor analysis, two types of contacts were used, "bonded" and "frictional." The first, for those who are rigidly attached, was used in the unions between spider hub plates, in the connection between arm and spider hub, in the contacts between arm, disks and reinforcements, in upper and lower shaft flange connections and spider hub, and in joints between rotor rim and poles. The other type was used in the assembly between the junction of the spider and rotor rim, and because it was steel-steel contact, a friction factor of 0.2 was used.

\subsection{Loading}

An entirely complex structure like the generator rotor has a diversity of loads, being some more relevant than others. The weight force from the generator and turbine rotation components is quite significant for the model. Therefore, each rotor piece was modeled with its real mass. Thus, when the acceleration of gravity is inserted into the program, it considers the weights of each element as a load. Besides, the weight of both non-modeled components (from the turbine), turbine rotor and its shaft, was considered in the model. Other axial effort that must be also considered as loading is the one resulting from the pressure of the water flow under the turbine wheel, known as hydraulic thrust. It creates axial forces that are transmitted to the generator rotor. This force plus non-modeled components of turbine is inserted into the model as axial force, shown in Fig. 7.

The machine rotational velocity comes straight on its members as centrifugal forces. There are three rotations that the generator unit may be subjected to: synchronous, overspeed and runaway. Figure 8 shows the model with rotation.

In order to assemble the rotor, it is necessary to apply a compressive force on the junction between spider and rotor rim. To do so, several forms of adjustment are employed, for instance, in the case studied this union is made by applying a pre-tension on screws that compresses the joint in the rotor rim. The aims are to do the transmission of the

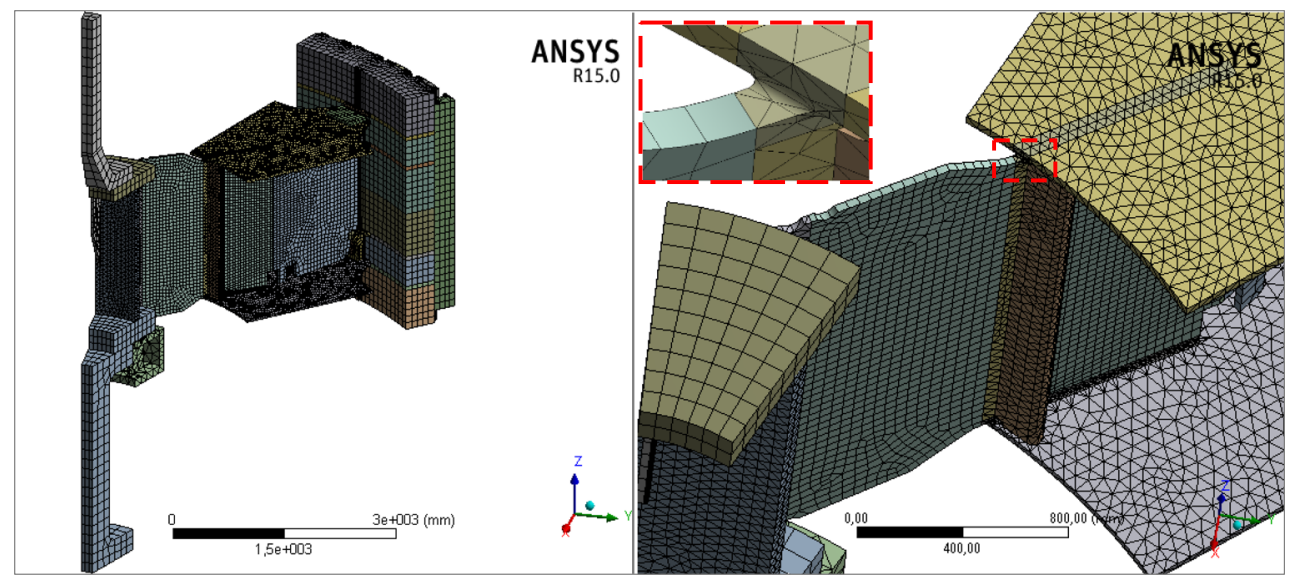

Fig. 5 Mesh without refinement 

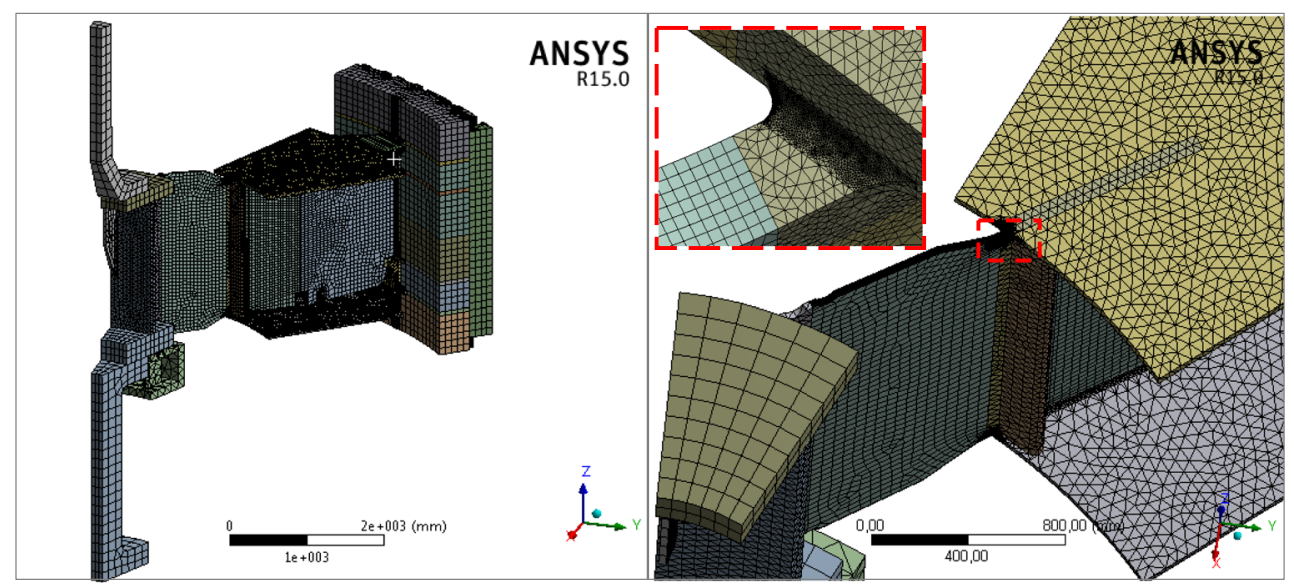

Fig. 6 Mesh with refinement

tangential forces and to unite the spider to the rotor rim. When the generator unit is stopped, this compressive force is maximum. If rotation is increased, this effort decreases until it reaches a rotation whose rotor rim expansion is sufficient to go down at zero with this compression load. This effect is known as rotor rim fluctuation because there is no more compressive radial force acting on this component, as if the rotor rim is "detached" from the spider. The speed of occurrence of this phenomenon is different for each machine, and it depends on a number of factors to determine its value. This effect occurs on synchronous rotation in Foz do Areia Hydropower Plant. Therefore, this compressive force will not be active when the machine is rotating higher than the synchronous velocity.

Finally, during the process of power transformation, the magnetic torque appears due to the attempt to align the magnetic fields to each pole. This torque has magnitude corresponding to the nominal power and will always be

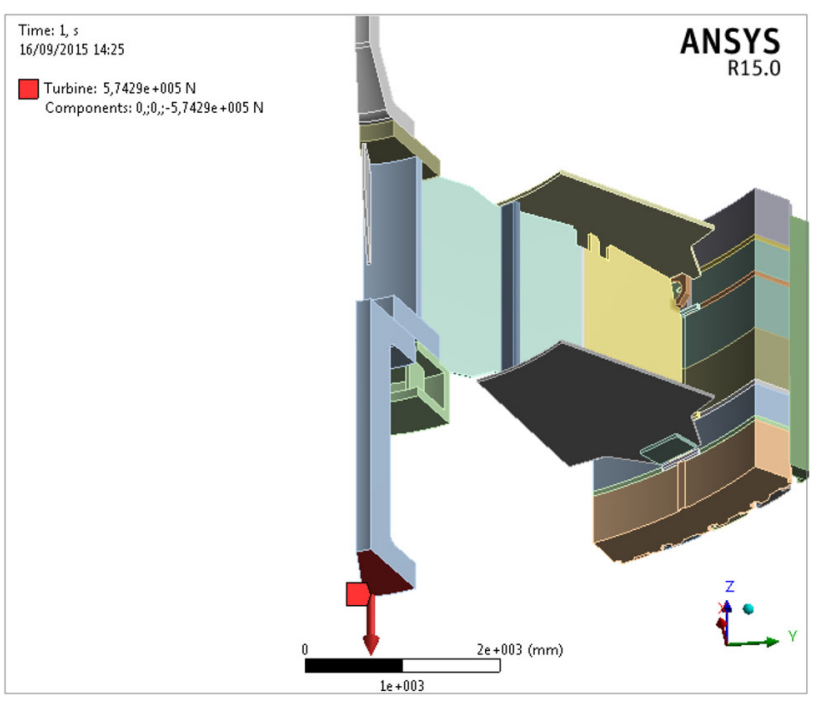

Fig. 7 Non-modeled components turbine force

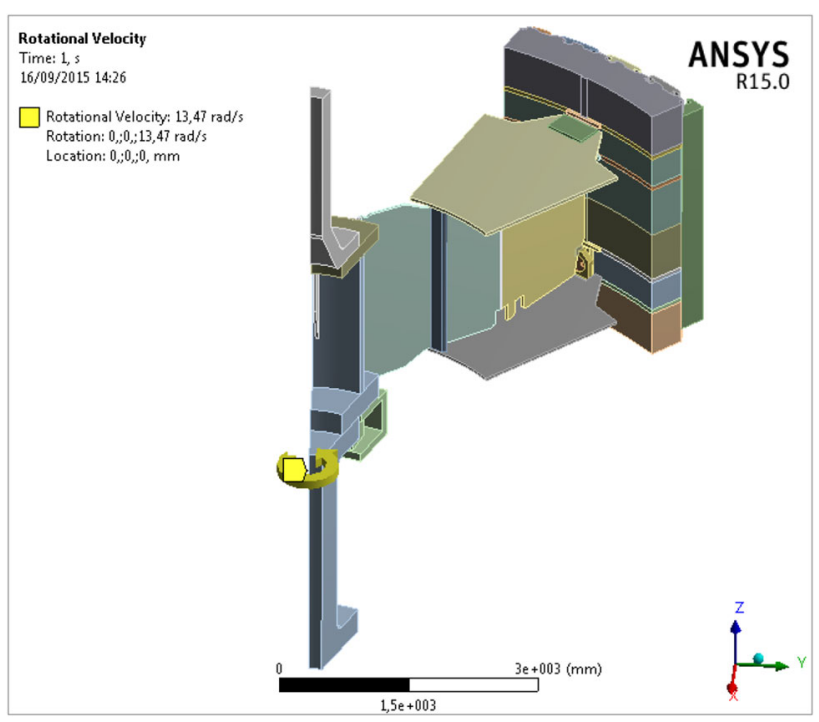

Fig. 8 Rotational velocity

contrary to the direction of the machine rotation. This type of effort is inserted into the model as tangential forces in each pole, as shown in Fig. 9.

\subsection{Load cases}

For the problem correct evaluation in several fronts it is necessary to establish load cases, for the studied machine works with different loadings. The following load cases were considered:

Load case 01-Stopped machine (weights and compressive force on the rotor rim).

Load case 02-Synchronous or nominal rotation (rotation, weights, torque and hydraulic thrust).

Load case 03-Overspeed (overspeed rotation, weights and maximum hydraulic thrust). 
The runaway condition will not be analyzed, because there is no history of this event occurrence in the studied hydrogenerator. Thus, for the fatigue life estimation the following cycles were considered:

Fatigue load case 01-Machine start and stop (stress alternates between cases 01 and 02 ).

Fatigue load case 02-Variation between synchronous rotation and overspeed (stress alternates between cases 02 and 03).

\subsection{Fatigue analysis}

The term fatigue is used in several areas with different meanings. In engineering, if a crack appears in a given structure and when it is or has been subjected to cyclic loading, it is said that the piece has failed due to fatigue.

The German August Wöhler has developed the first scientific research on fatigue failures. In 1870, his findings were published establishing the existence of a limit stress of fatigue resistance to steels or a stress level that would admit millions of alternating stress cycles. The $\mathrm{S}-\mathrm{N}$ diagram or Wöhler curve, which is still used nowadays, has become the standard to evidence the behavior of materials requested with cyclic loads.

In $\mathrm{S}-\mathrm{N}$ curve it is observed that the higher the number of cycles $(\mathrm{N})$, the lower the resistance to fatigue (S). Thus, an uncorrected endurance limit (Se') is defined as the stress level below of which there will be no fatigue failures. In order to determine the Se' of any material, the performance of several tests besides the demand of a long time and, consequently, the involvement of high costs are necessary. Thus, it is possible to find data that point out the fatigue limit value for different material types in several

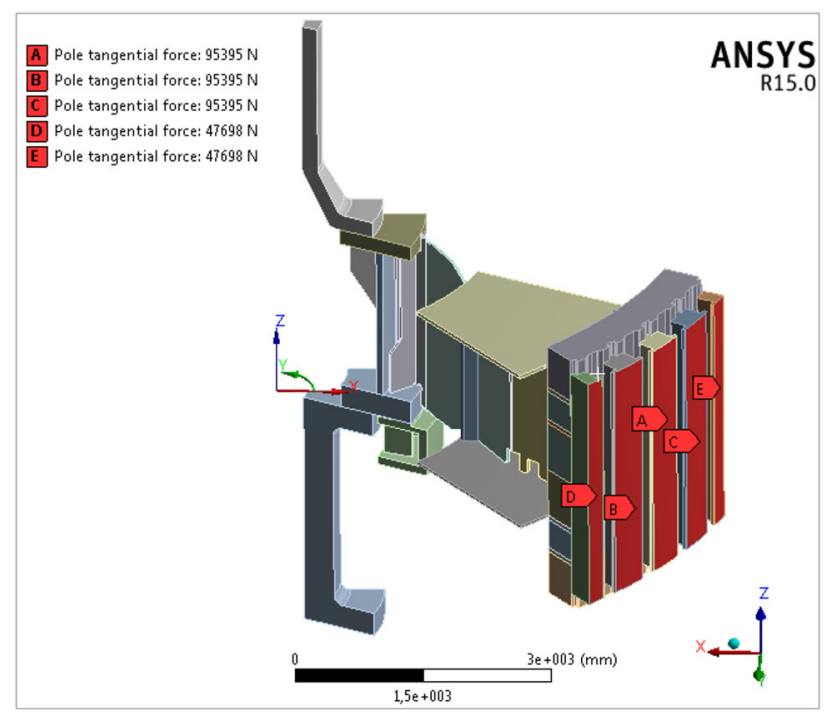

Fig. 9 Tangential forces bibliographies. Norton [1] estimated the Se' for steels in general according to the equation below:

$\left\{\begin{array}{l}S_{e^{\prime}} \cong 0,5 S_{\mathrm{ut}} \quad \text { for } S_{\mathrm{ut}}<200 \mathrm{ksi}(1400 \mathrm{MPa}) \\ S_{e^{\prime}} \cong 100 \mathrm{ksi}(700 \mathrm{MPa}) \text { for } S_{\mathrm{ut}} \geq 200 \mathrm{ksi}(1400 \mathrm{MPa})\end{array}\right.$

The limits of fatigue strength obtained through standard test specimens or from estimates based on static evaluations should be corrected in order to consider the physical differences between the specimens and the genuine studied structure. This correction is made with the use of resistance reduction factors $[1,11]$ that take into account differences in temperature, environment, loading, geometry and others. Hence, the corrected endurance limit (Se) or the corrected fatigue strength (Sf) is obtained through the expression.

The uncorrected endurance limit (Sé) stands for the limit of stress life endurance of ideal laboratory samples. In order to predict the corrected endurance limit (Se) for a mechanical component, Sé has to be multiplied by several modifying factors which represent several design, manufacturing and environmental influences on the fatigue strength $[1,11]$. "Se" is given as

$S_{e}=C_{\text {load }} C_{\text {size }} C_{\text {surf }} C_{\text {temp }} C_{\text {reliab }} S_{e \prime}$

\subsubsection{Loading factor $C_{\text {load }}$}

The fatigue strength of several materials is obtained through rotational bending tests. There are differences between this fatigue strength obtained experimentally and the real one of the piece, so a factor is defined due to the resistance reduction request $\left(C_{\text {load }}\right)$. This value will be equal to 1 , if it is pure bending and torsion and 0.7 if it is normal force. In this study, the factor is equal to 1 because the request is a bending effort.

\subsubsection{Size factor $C_{\text {size }}$}

All test specimens have small dimensions. Generally, the evaluated members are larger than the specimens, and thus, it is necessary to use the size factor to decrease the resistance, because larger pieces fail with lower tensions. The equation below valid only for cylindrical pieces, considered conservative, according to Shigley et al. [11] presents the calculation of the size effect.

$C_{\text {size }}=1$ for $d \leq 8 \mathrm{~mm}$

$C_{\text {size }}=1.189 d^{-0.097}$ for $8 \mathrm{~mm}<d \leq 250 \mathrm{~mm}$

where $d$ is the component diameter.

For non-circular cross sections, according to Kuguel [12] the approach to be used employs an equivalent diameter (d) obtained by equating the volume of material 
stressed at and above $95 \%$ of the maximum stress to the same volume in the rotating beam specimen. It turns out that when these two volumes are equated, the lengths cancel, and so it considers the areas. Thus, designating the 95 percent stress area A95, the equivalent diameter is

$d=\sqrt{\frac{A_{95}}{0.0766}}$

Thus, the value found for $C_{\text {size }}$ at the two critical points of maximum stress (crack region) is 0.908 .

\subsubsection{Surface factor $C_{\text {surf }}$}

The surface finish performed on test specimens is different from the real pieces produced. Therefore, a surface factor, $C_{\text {surf }}$, should be used to reduce the resistance and consider the difference in finish. According to Shigley et al. [11] the calculation of surface factor is given as

$C_{\text {surf }} \cong A\left(S_{\mathrm{ut}}\right)^{b}$

The parameters of equation 5 can be obtained from Table 4 below, according to Shigley et al. [11]. Table 4 Coefficients for surface factor equation, for Sut in [MPa].

The material of critical rotor generator components is hot-rolled, so recommended values are $A=57.7$ and $b=-0.718$. For rotor spider arms (critical component that appeared cracks) the calculated value is $C_{\text {surf }}=0.781$ for $S_{\text {ut }}=400.0 \mathrm{MPa}$.

\subsubsection{Temperature factor $C_{\text {temp }}$}

Frequently, thermal fatigue tests are performed at ambient temperature. Since many components act at high temperatures, it is also necessary to correct fatigue resistance. The values proposed by Shigley, Mischke and Budynas [11] for steels are given in equation below.

$C_{\text {temp }}=1$ for $T \leq 450{ }^{\circ} \mathrm{C}$

$C_{\text {temp }}=1-0.0058(T-450)$ for $450<T \leq 550{ }^{\circ} \mathrm{C}$

As the temperatures in the rotor spider are close to ambient temperature, then the temperature factor is equal to 1 .

Table 4 Coefficients for surface factor equation, for $S_{\mathrm{ut}}$ in [MPa]

\begin{tabular}{lrl}
\hline Surface finish & \multicolumn{1}{l}{$A$} & \multicolumn{1}{l}{$b$} \\
\hline Ground & 1.58 & -0.085 \\
Machined or cold-drawn & 4.51 & -0.265 \\
Hot-rolled & 57.70 & -0.718 \\
As-forged & 272.00 & -0.995 \\
\hline
\end{tabular}

\subsubsection{Reliability factor $C_{\text {reliab }}$}

According to Norton [1], Table 5 shows the reliability factors with a standard deviation of $8 \%$ of their mean values.

Assuming that a reliability equals to $99.9 \%$, the reliability factor $C_{\text {reliab }}$ is 0.753 .

Therefore, according to Eq. 2 the total correction factor that should be entered in the numerical simulation program is 0.53 .

The materials of the most critical components related to fatigue have similar mechanical properties. An example of one of them is the ultimate strength less than 552.0 MPa. Thus, in the regions of fatigue analysis, a common $\mathrm{S}-\mathrm{N}$ curve is used between the pieces, as shown in Fig. 10.

From the alternating stress value obtained by the ANSYS program, at each point of interest, and considering the correction factors, it is possible to obtain the number of cycles by means of $S-N$ curve and consequently the fatigue lifetime.

\section{Results and discussion}

\subsection{Static analysis}

The stresses that symbolize all effects the best are the Von Mises equivalent stresses as they represent three-dimensional state stresses or combined stresses, which means that the stresses presented must be classified for analysis and according to their type and criticality.

Figure 11 shows the stress state in the complete structure for the stopped machine condition (load case 01 ). The member that presented the most significant stresses, the rotor spider, is detailed in Fig. 12. Note that the maximum stress is classified as secondary because, according to the ASME code [10], a constraint imposed on one component by another of higher stiffness causes secondary stresses in the region of analysis. However, as well as the stresses in all rotor members, their value is below the permissible general primary membrane stress and, therefore, there is no need to check and classify the other types of stress.

Table 5 Reliability factors

\begin{tabular}{ll}
\hline Reliability & $C_{\text {reliab }}$ \\
\hline 50 & 1.000 \\
90 & 0.897 \\
99 & 0.814 \\
99.9 & 0.753 \\
99.99 & 0.702 \\
99.999 & 0.659 \\
\hline
\end{tabular}




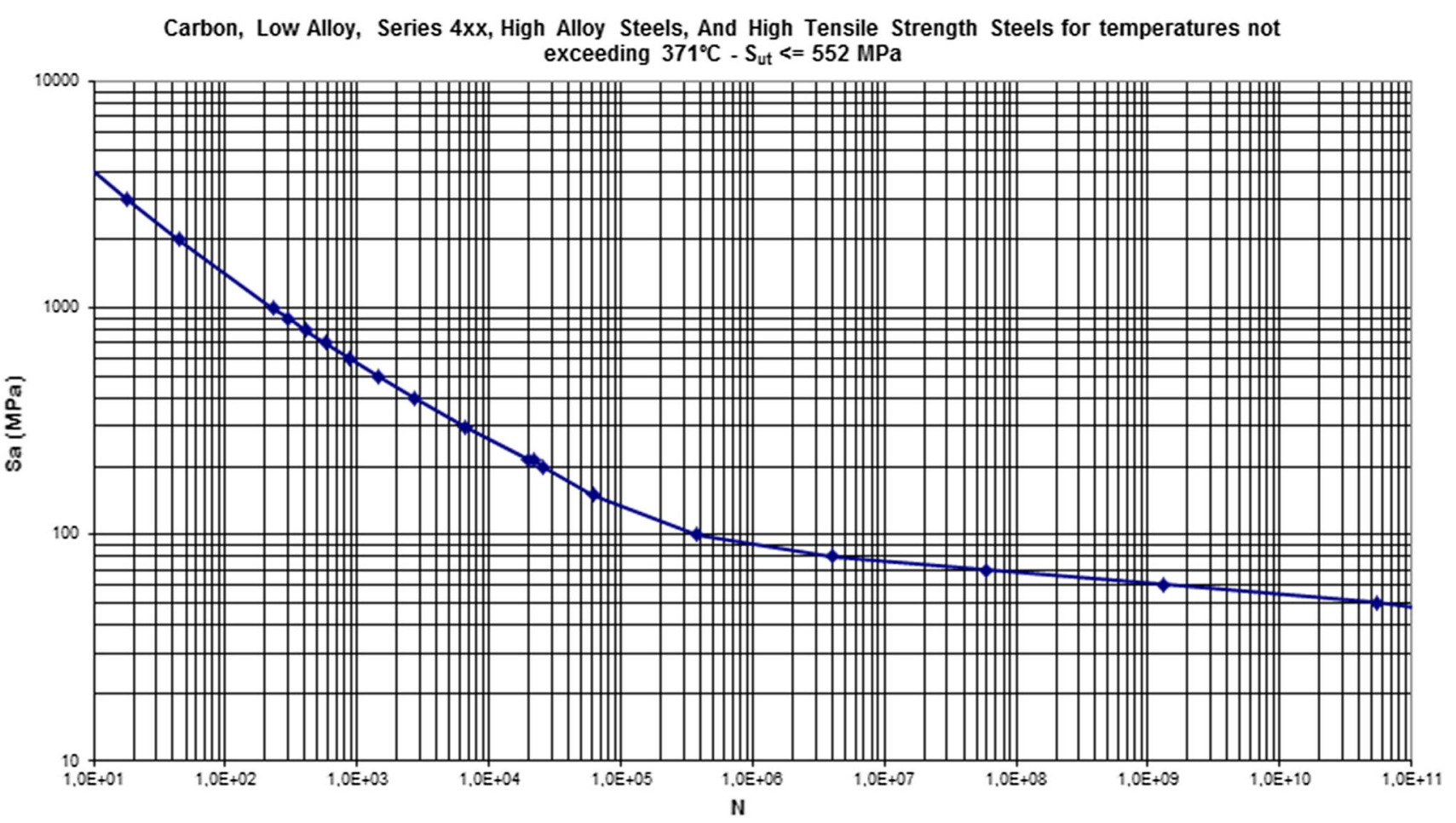

Fig. $10 \mathrm{~S}-\mathrm{N}$ curve of rotor spider component materials

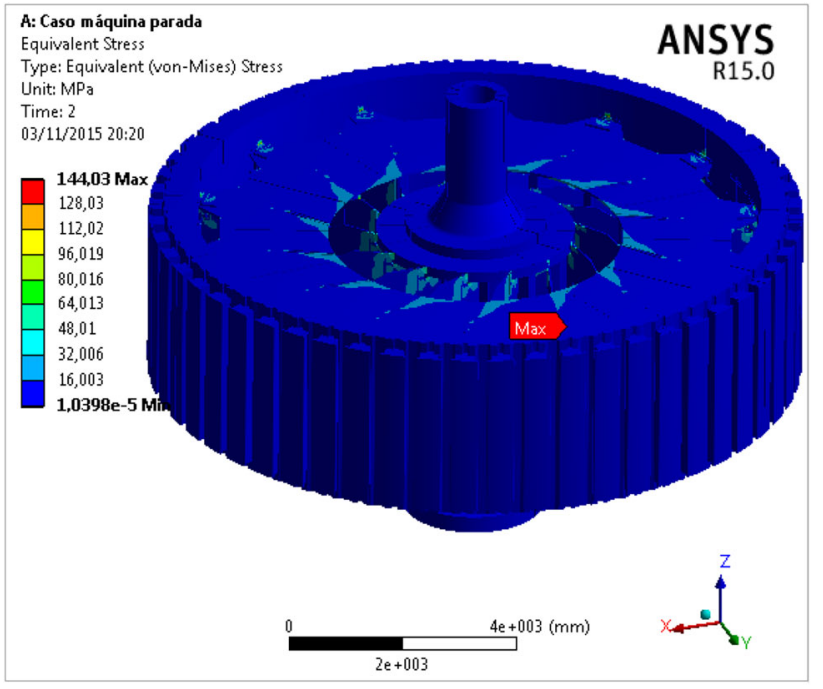

Fig. 11 Rotor Von Mises stress-load case 01

For the synchronous rotation case (load case 02) the stresses increase considerably due to the presence of rotation, as can be observed in Fig. 13. Isolating the structure in which were observed relevant stresses, according to Fig. 14, it is possible to detail the regions with maximum stress values. It is also verified that the tension $\mathrm{Pl}+$ $\mathrm{Pb}+\mathrm{Q}$ between hub and rib, 201.4 MPa, is below the criteria. The maximum stress in the transition zone between spider arm and upper/lower disk (weld),
361.64 MPa and 334.45 MPa, respectively, is classified as peak, and therefore, a fatigue analysis needs to be done.

In order to obtain the other types of stresses, a linearization along the thickness of the arm is necessary, passing through the point of maximum stress, according to ASME [10]. From the graph of Fig. 15, the upper transition stresses, $\mathrm{Pm}=32.17 \mathrm{MPa}$ and $\mathrm{Pl}+\mathrm{Pb}=189.06 \mathrm{MPa}$, are obtained and both of them are lower than the admissible ones.

Similarly, in the lower weld, the values of each stress type are obtained, according to Fig. 16. In this transition zone, the general primary membrane stress is $38.38 \mathrm{MPa}$ and the local primary membrane stress plus the primary bending stress, whose maximum value is $175.28 \mathrm{MPa}$, also meets the respective adopted criteria and therefore does not provide static failures.

The overspeed condition (load case 03 ) has the highest stresses due to its high rotation. This situation occurs occasionally, and therefore, it is not considered as a normal operating condition. The values of Von Mises stresses are shown in Fig. 17, and afterward, the behavior of stresses in the spider (most critical part of the rotor), as observed in Fig. 18, is also shown. The maximum stress in the transition from the spider hub to the rib (210.24 MPa), classified as $\mathrm{Pl}+\mathrm{Pb}+\mathrm{Q}$, meets the respective limit. The stress state is detailed in regions of high criticality, whose maximum values are also classified as peak stresses, and will still be evaluated by fatigue in the next items. The other non-detailed regions have stresses from below the criteria 

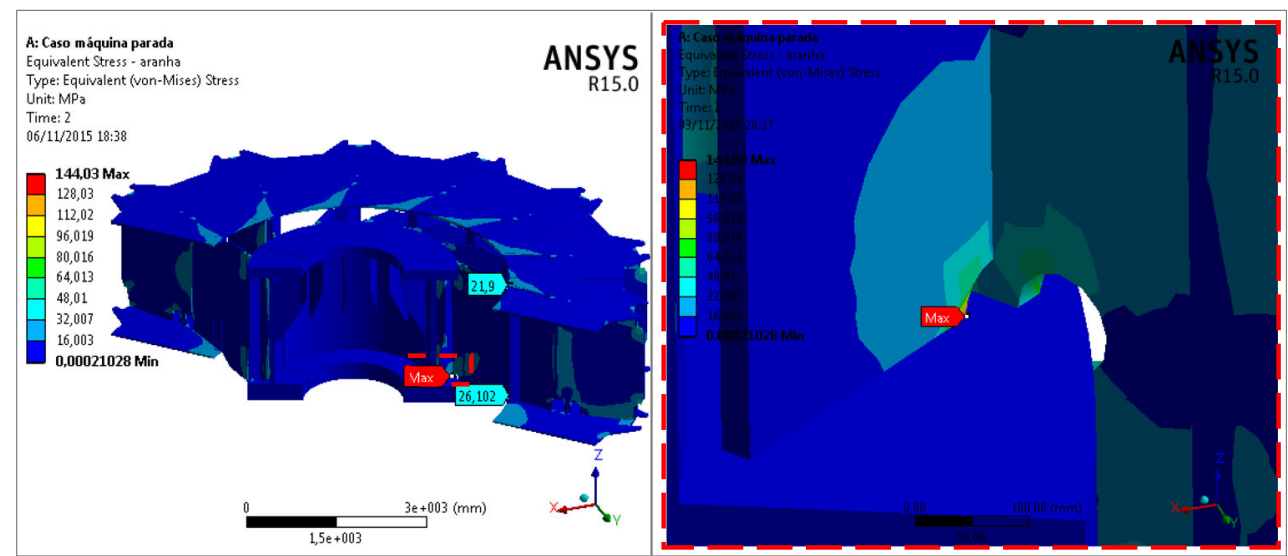

Fig. 12 Rotor spider Von Mises stress-load case 01

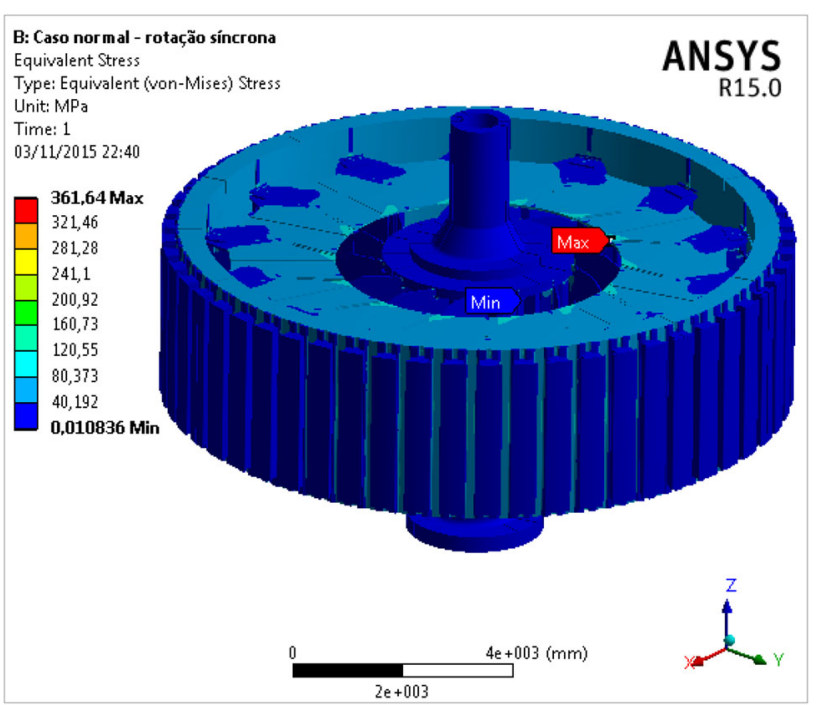

Fig. 13 Rotor Von Mises stress-load case 02

to general primary membrane and therefore meets the criteria with a good safety margin.

The general primary membrane stresses and local primary membrane plus primary bending stresses are shown in Fig. 19 and Fig. 20. It is observed that the values $\mathrm{Pm}=39.36 \mathrm{MPa}, \mathrm{Pl}+\mathrm{Pb}=235.01 \mathrm{MPa}$ in upper part and $\mathrm{Pm}=44.42 \mathrm{MPa}, \mathrm{Pl}+\mathrm{Pb}=206.85 \mathrm{MPa}$, in lower part, also did not exceed their limits, so there are no static problems.

The maximum stress values obtained for each load case in the most critical component of the rotor (spider) can be seen in Table 6.

\subsection{Fatigue analysis}

According to the results shown in item 4.1, a fatigue analysis should be done in the arm transition regions with the upper and lower disks of spider. The following results will be presented only in the rotor spider, because in other components there are no relevant alternating stresses.

The alternating stress for fatigue load case 01 is calculated from the Von Mises stress obtained in the case of a stopped machine and a normal operating condition (synchronous rotation). By making a combination of results in the ANSYS program, it is possible to reach the values of alternating stress and, consequently, to obtain the fatigue life. Figure 21 shows the values found for alternating stress

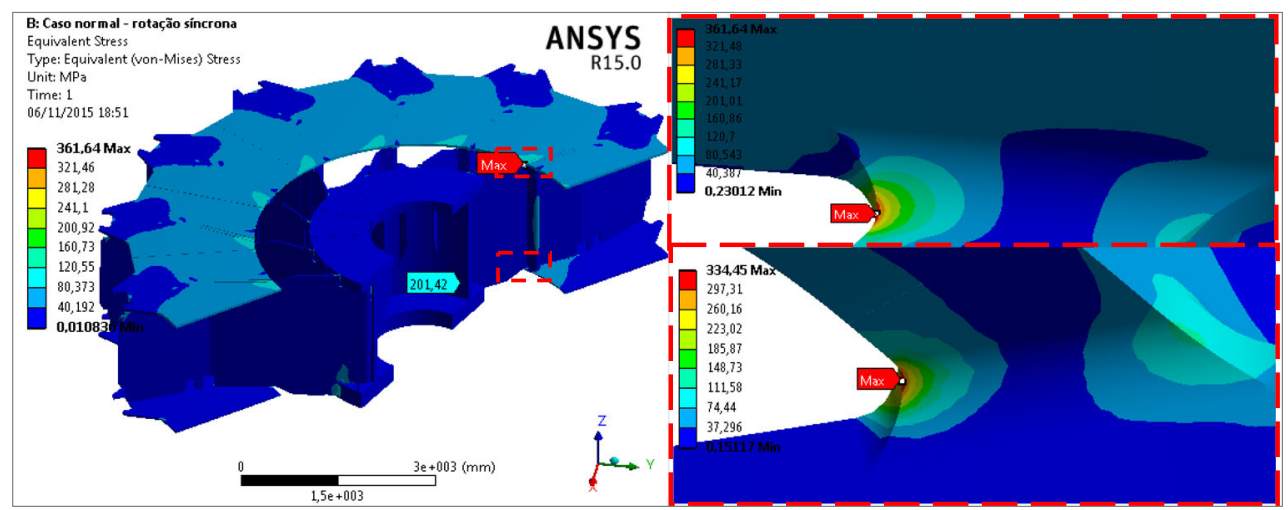

Fig. 14 Rotor spider Von Mises stress-load case 02 


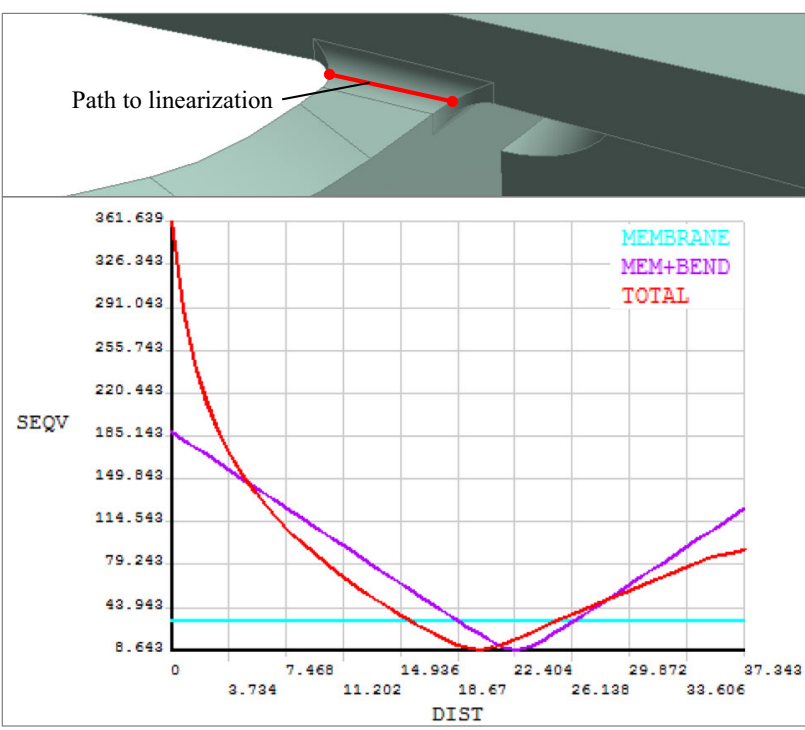

Fig. 15 Stress linearization upper region-load case 02

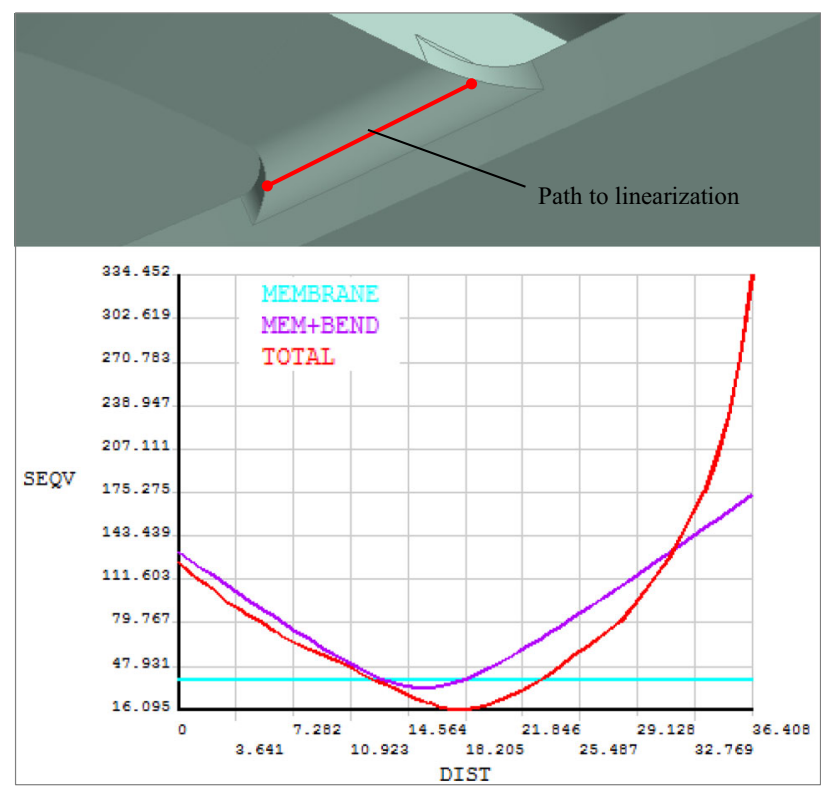

Fig. 16 Stress linearization lower region-load case 02

in spider. As expected, the maximum and the most significant values appeared in the transition regions between arm and disks (weld).

From the values of alternating stress, it is possible to get the number of cycles of the fatigue life through the material SN curve (Fig. 10). For the start and stop machine condition, the number of cycles in two critical regions is 1075.3 cycles or 39 cycles per year (considering 27 years) in transition of arm with upper disk and 1668.9 cycles or 61 cycles per year (in a total of 27 years) in the opposite region. Therefore, if the number of machine stops reaches

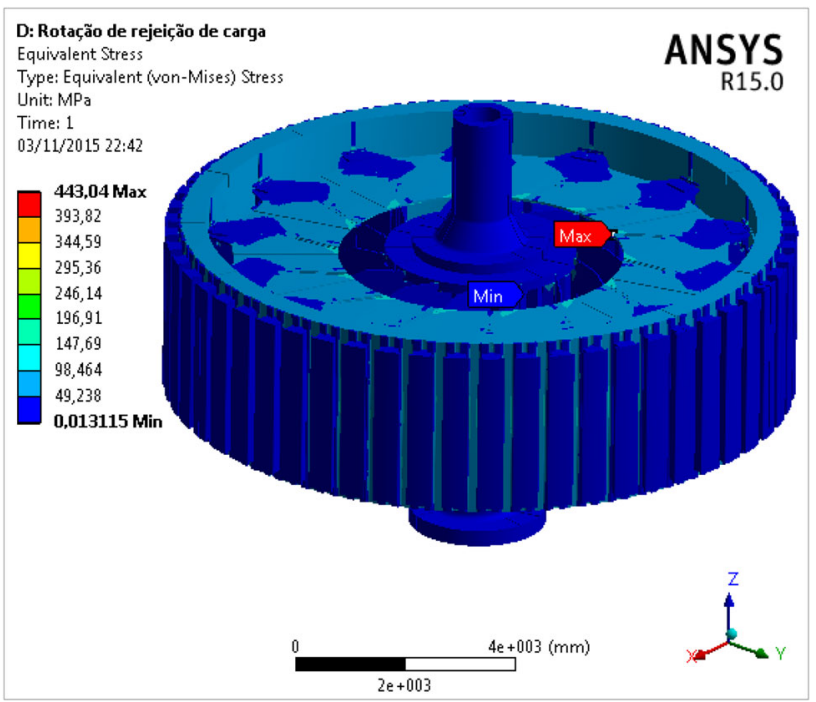

Fig. 17 Rotor Von Mises stress-load case 03

four or more in the month, then there will be failure due to fatigue.

The oscillation between the nominal rotation and overspeed conditions also produces alternating stresses in the rotor. Again, these stresses were not expressive in all rotor components except in the spider. Through Fig. 22, it is possible to notice that the critical regions are maintained in the transition from the arm to the disks.

Therefore, the number of cycles supported by the spider in fatigue load case 02 is 883 cycles in upper region and 6463.3 cycles in the lower, which represents, respectively, 32 cycles per year and 239 cycles per year for 27 years. Hence, fatigue occurs from three overspeed per month.

\subsection{Relief radius greater analysis}

To reduce stresses and increase fatigue life, a study was performed considering a three-millimeter increase relief radius of welds at arm and disk junction. The value of this parameter is very sensitive to the obtained results, and it can be a simple and quick solution to prolong the life of the piece. If the machine is stopped, the change has no effect because the stresses in these regions are quite low. As an evaluation for the life increase, Fig. 23a shows the stress values for the nominal rotation condition. The maximum stress reduced to around $21 \%$. (The same reduction can be considered for load case 03.) Therefore, the alternating stress for the start and stop condition according to Fig. 23b presented a decrease of $30 \%$. This fact generates 3007.6 life cycles or 111 cycles per year (a significant increase in fatigue life). 


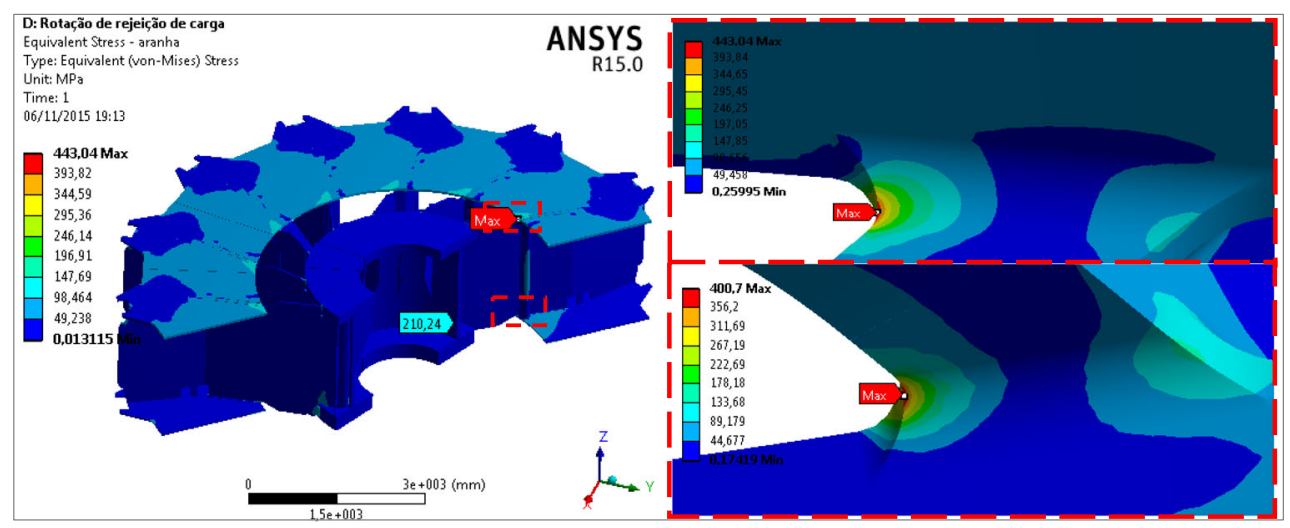

Fig. 18 Rotor spider Von Mises stress-load case 03

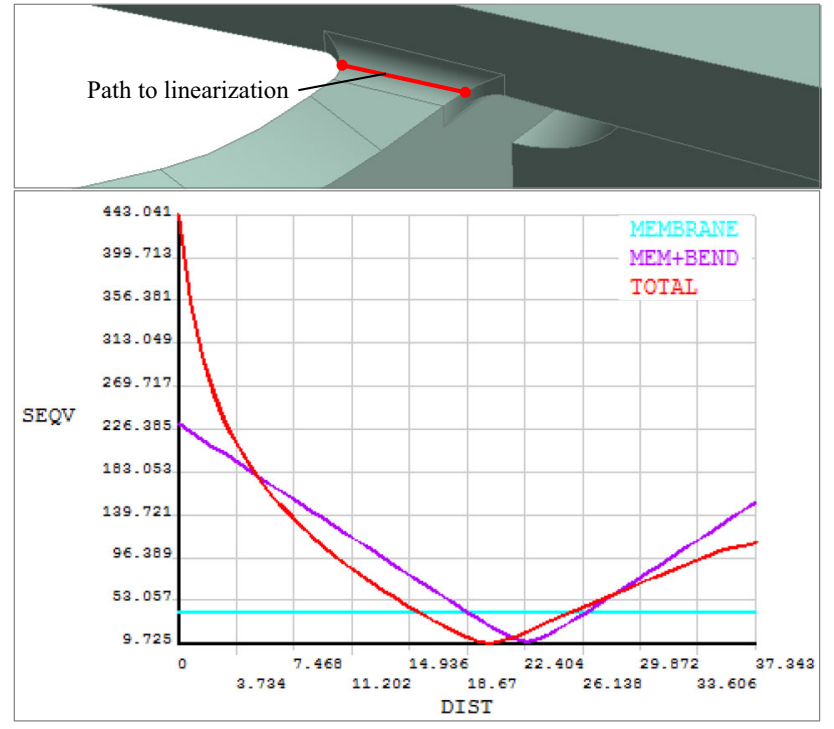

Fig. 19 Stress linearization upper region-load case 03

\section{Conclusions}

The three-dimensional model of the complete rotor allowed very satisfactory results. The comparison of these values with the realistic perception permits to understand the main efforts on the structure and, consequently, to determine the cause of the failures. It was important to model and to know the interfaces between all of the rotor components, for each of them contributes with its stiffness and has a direct influence on results. The program used in numerical simulation is able to solve the problem quickly and accurately if there is the correct insertion of loading and boundary conditions, in addition to a coherent mesh that meets the analysis characteristics.

The results presented for the static conditions (load cases 01, 02 and 03) meet all the established criteria, and hence, there is no damage of this failure type.

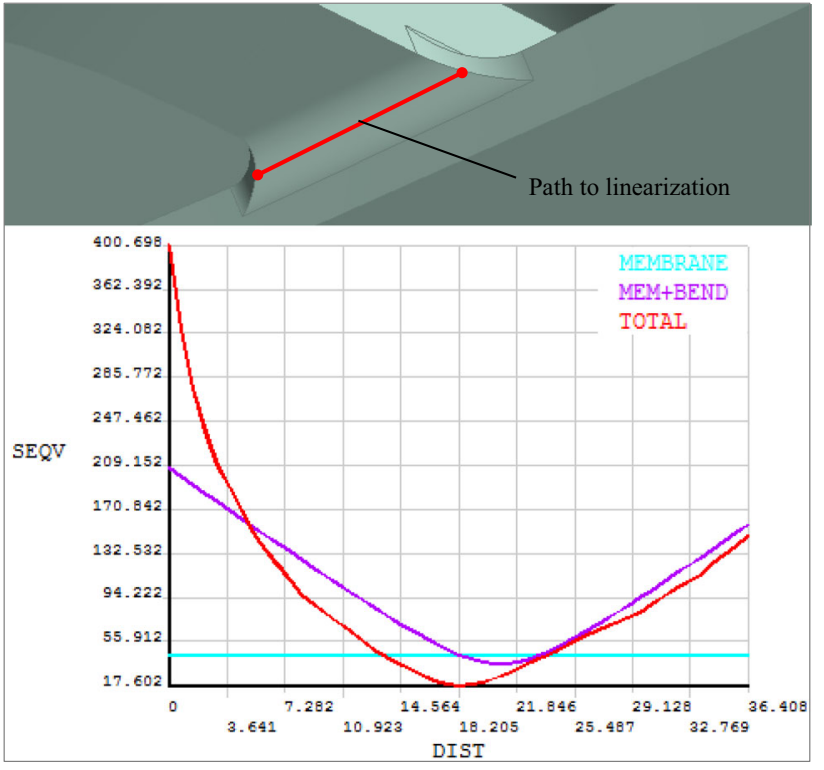

Fig. 20 Stress linearization lower region-load case 03

The fatigue life analysis of the rotor components has identified problems in the interface regions between spider arm and disks (upper and lower). Thus, it was possible to confront them with the cracks that were observed in the same areas. All other rotor parts present a much longer life, so they are not of concern. For the variation between normal condition and overspeed rotation, fatigue load case 2 , almost three cycles per month were reached during 27 years (time in which the damage was perceived). Although it is a small value, it is slightly above of an overspeed per month, which is a common data for this kind of machine. However, any change in the behavior of the unit can compromise the structure in this condition. The value of the number of cycles set for the alternate loading condition between start and stop of the machine corresponds to a little over three stops per month in 27 years. Thus, as this is a smaller number than the one commonly practicable in several hydroelectric plants (one to three 
Table 6 Critical regions maximum stresses

\begin{tabular}{lcll}
\hline Region & Load case 01 $(\mathrm{MPa})$ & Load case 02 (MPa) & Load case 03 (MPa) \\
\hline Hub and rib transition & 144.0 & 201.4 & 210.2 \\
Arm and upper disk transition & 21.9 & 361.6 & 443.0 \\
Arm and lower disk transition & 26.1 & 334.5 & 400.7 \\
\hline
\end{tabular}

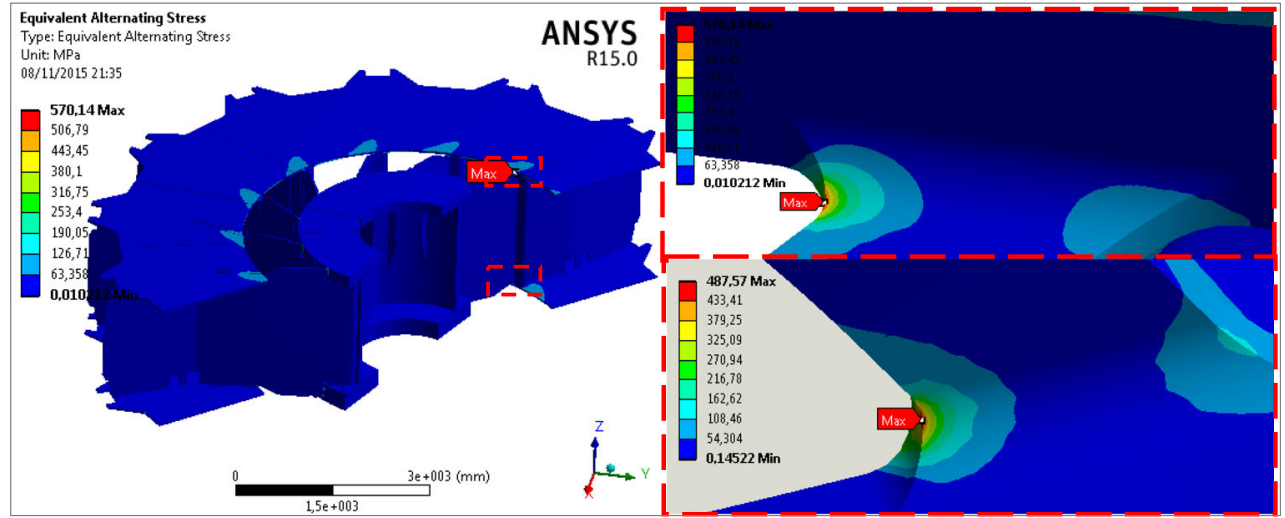

Fig. 21 Rotor spider alternating stress-fatigue load case 01

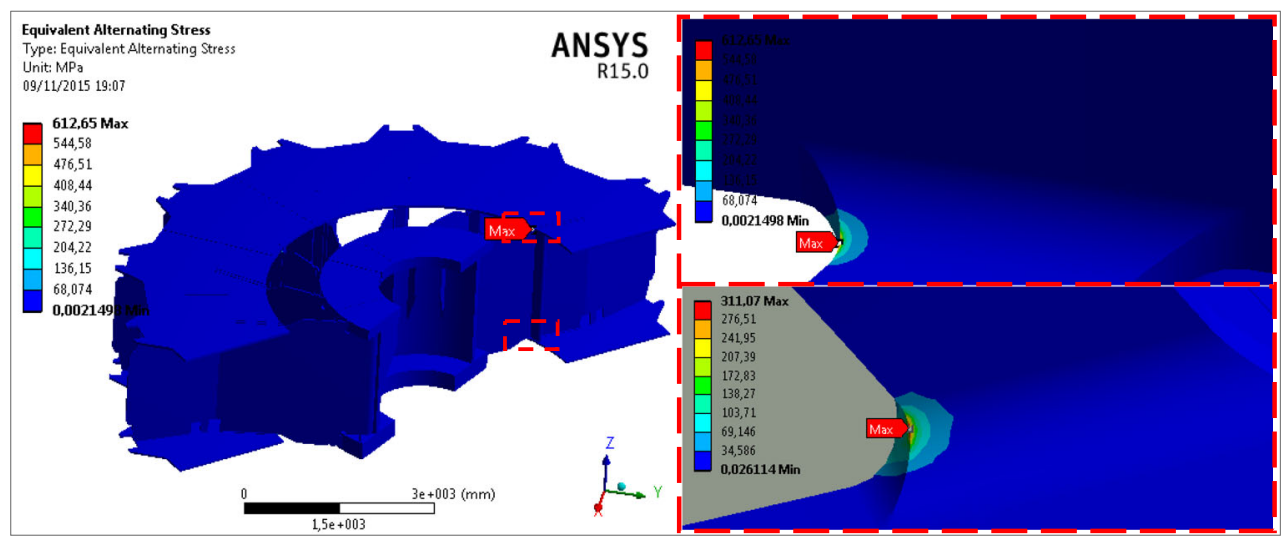

Fig. 22 Rotor spider alternating stress-fatigue load case 02

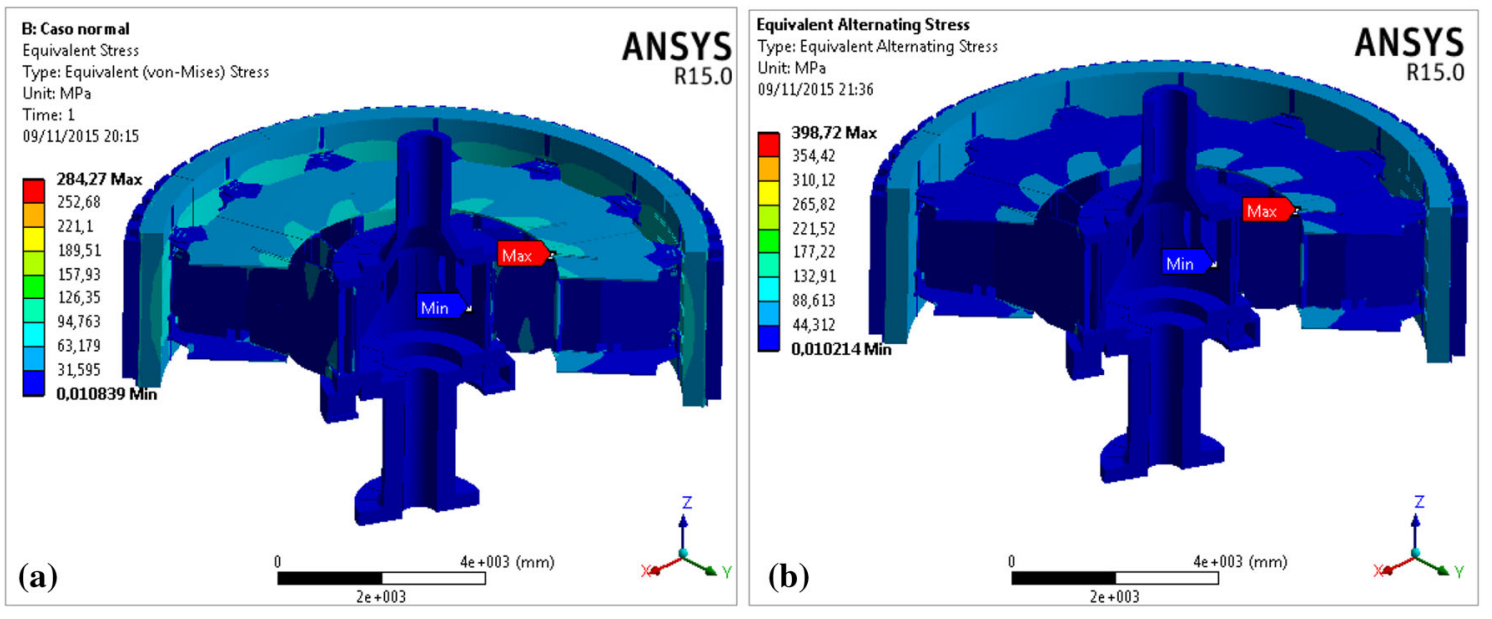

Fig. 23 a Rotor Von Mises stress—-load case 02; b rotor alternating stress-fatigue load case 01 
stops a day or one per week), it can be said that the cracks are due to the fatigue. However, since there is no history of the number of stops occurred in this period as well as the number of overspeed, there is no way to obtain the approximate time for damage beginning. As a result, it is impossible to state whether the defects have arisen only by fatigue or by a composition with another damage type (vibration).

The relief radius of the weld at the areas of damage is decisive in the stresses calculation. Then, any change in its value has direct implication in fatigue life result in this area. It is of extreme importance that the real piece has its relief radius very well defined and it is manufactured with projected dimensions, for the absence of relief in the welds and differences between fabrication/design imply in a great increase in stresses and thereafter, abruptly reduce the life in this area causing damage to structure. An easily adaptable increase of three (3) millimeters in relief radius rises by three times approximately the number of cycles in critical transition zones, and it is a good alternative to increase fatigue life of the structure and to prevent damage recurrence.

The material mechanical properties, especially yield and rupture strength, are also extremely relevant for any structural evaluation of mechanical components such as static and fatigue analysis. Not always, the sheets for manufacturing rotor elements have the same properties as those specified by standards. That is why it is essential to validate these values. Any significant change of properties has a direct impact on the admissible stresses and on SN curve.

Finally, the numerical simulation using finite element method has evidenced to be an extremely important tool in several work fronts. The calculation program has met expectations within its limits for the study of vertical hydrogenerator rotor fatigue. Approximations that could be avoided in other types of methods were necessary. On the other hand, some representations that were not simplified here should be carried out in other practices. Therefore, any complex calculation will have approximations, regardless of the method used. Thus, it takes some professional experience to employ the ideal tool to meet the expectations and to allow approximating the simulation of reality.

\section{References}

1. Norton RL (2013) Machine design—an integrated approach. Pearson Education, London

2. Pettersson G, Barsoum Z (2012) Finite element analysis and fatigue design of a welded construction machinery component using different concepts. Eng Fail Anal 26:274-284

3. Willmerding G, Häckh J, Radovcic Y (2011) Fatigue life design for wind turbine components using WinLIFE. Nafems World Congress, Boston

4. Xiang H et al (2012) Fatigue analysis of the rotor shaft on a high speed traction motor. Adv Mater Res 482-484:722-725

5. Feng L, Liu X, Xuan F (2014) Simulation of residual stress in welded steam turbine rotor and its effects on fatigue life. Chin Soc Electr Eng 34(17):2851-2860

6. El-sayed HM et al (2017) Prediction of fatigue crack initiation life in railheads using finite element analysis. Ain Shams Eng J. https://doi.org/10.1016/j.asej.2017.06.003\&gt

7. Hildinger $\mathrm{T}$ et al (2015) Fatigue Assessment on Hydro Generator Pole Fixation. In: ERIAC-Decimosexto Encuentro Regional Iberoamericano de Cigré, Puerto Iguazú. Máquinas Eléctricas Rotativas. A1-13

8. Boldea I (2006) Synchronous generators. Taylor \& Francis Group, Boca Raton

9. Fink DG, Beaty HW (2006) Standard handbook of electrical engineering. Mc Graw-Hill, New York

10. ASME Boiler \& Pressure Vessel Code Section VIII division 2 (2013)

11. Shigley JE, Mischke CR, Budynas RG (2005) Projeto de Engenharia Mecânica. Bookman, Porto Alegre

12. Kuguel R (1961) A relation between theoretical stress-concentration factor and fatigue notch factor deduced from the concept of highly stressed volume. Proc ASTM 61:732-748 